\title{
Correction: Impact of river reconstruction on groundwater flow during bank filtration assessed by transient three-dimensional modelling of flow and heat transport
}

\author{
Wei-shi Wang ${ }^{1}$ - Sascha E. Oswald ${ }^{1} \cdot$ Thomas Gräff $^{1,2} \cdot$ Hermann-Josef Lensing ${ }^{3} \cdot$ Tie Liu $^{4} \cdot$ Daniel Strasser $^{3}$. \\ Matthias Munz ${ }^{1}$
}

Published online: 3 August 2020

(C) Springer-Verlag GmbH Germany, part of Springer Nature 2020

Correction: Hydrogeology Journal (2020) 28:723-743

https://doi.org/10.1007/s10040-019-02063-3

The original version of this article unfortunately contained mistakes.

The affiliation of Daniel Strasser is hereby corrected to:

Department of Geotechnical Engineering, Federal Waterways Engineering and Research Institute (BAW), Kussmaulstraße 17, 76187 Karlsruhe, Germany

The original Figure $1 \mathrm{~b}$ contains an error with respect to the reconstruction dates. The corrected figure is given here.

The online version of the original article can be found at https://doi.org/ 10.1007/s10040-019-02063-3

\section{Wei-shi Wang}

wewang@uni-potsdam.de

1 Institute of Environmental Science and Geography, University of Potsdam, Karl-Liebknecht-Str. 24-25, 14476 Potsdam, Germany

2 Presently at German Environment Agency (UBA), Woerlitzer Platz, 1, 06844 Dessau-Rosslau, Germany

3 Department of Geotechnical Engineering, Federal Waterways Engineering and Research Institute (BAW), Kussmaulstraße 17, 76187 Karlsruhe, Germany

4 State Key Laboratory of Desert and Oasis Ecology, Xinjiang Institute of Ecology and Geography, Chinese Academy of Sciences,

Urumqi 830011, China 


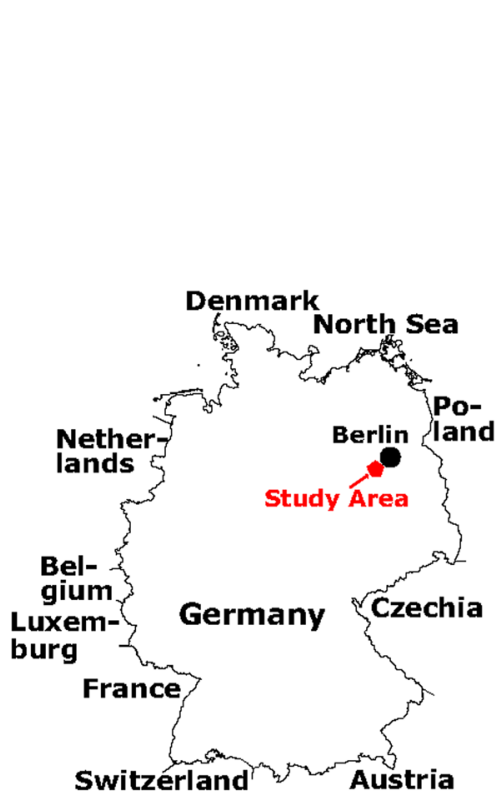

a)

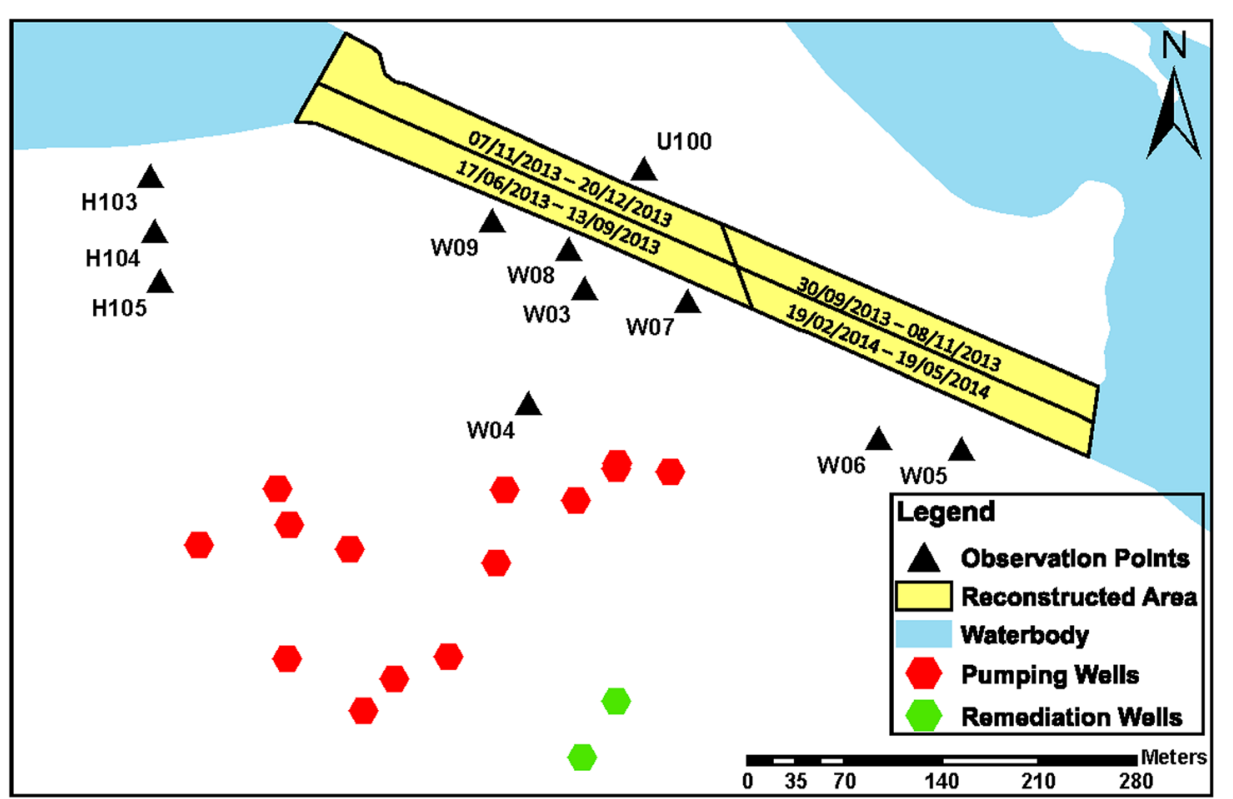

b)

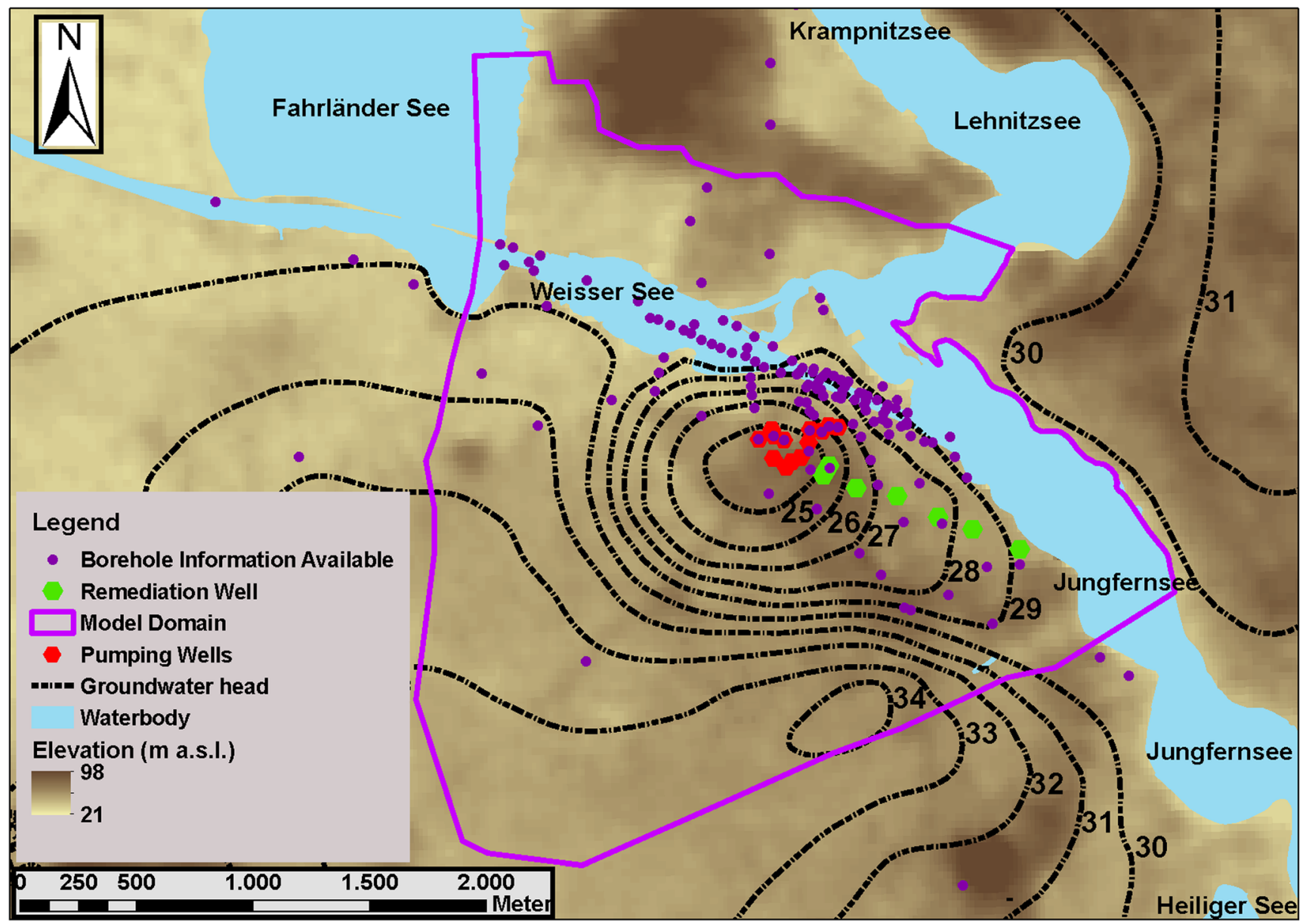

c)

Fig. 1 a Location of Potsdam in Germany. b Location of observation wells and pumping wells beside the ND canal (yellow area, divided based on the effective schedule of reconstruction in the ND). c Study area with groundwater equipotential lines ( $m$ a.s.l.) of the uppermost aquifer, location of pumping and remediation wells, and the location of all borehole profiles used to design the geological model structure. Background map of DEM was adopted from NASA's Land Processes Distributed Active Archive Center (LP DAAC) (2019) accessed on 24 September 2019 